\title{
A Novel Rough Range of Value Method (R-ROV) for Selecting Automatically Guided Vehicles (AGVs)
}

\author{
Edmundas Kazimieras ZAVADSKAS ${ }^{1 *}$, Zdravko NUNIĆ ${ }^{2}$, \\ Željko STJEPANOVIĆ ${ }^{2}$, Olegas PRENTKOVSKIS ${ }^{3}$ \\ ${ }^{1}$ Vilnius Gediminas Technical University, Institute of Sustainable Construction, Saulettekio al. 11, LT-10223 \\ Vilnius, Lithuania \\ edmundas.zavadskas@vgtu.lt (*Corresponding author) \\ ${ }^{2}$ University of East Sarajevo, Faculty of Transport and Traffic Engineering, Vojvode Mišića 52, 74000 Doboj, \\ Bosnia and Herzegovina \\ zdravko.nunic@sf.ues.rs.ba; zeljko.stjepanovic@sf.ues.rs.ba \\ ${ }^{3}$ Vilnius Gediminas Technical University, Faculty of Transport Engineering, Department of Mobile Machinery \\ and Railway Transport, Plytinès g. 27, LT-10105 Vilnius, Lithuania \\ olegas.prentkovskis@vgtu.1t
}

\begin{abstract}
Material Handling Equipment is a set of different tools, devices, applications that aim to facilitate the handling of materials and products. It is used inside the warehouse, but also between warehouses and production facilities. As an important type of material handling equipment, automatically guided vehicles (AGVs) play one of the key roles in warehouse automation. The benefits of applying the AGVs in the warehouse automation process include: reducing labor costs, increasing reliability and productivity, reducing the damage of goods, safety improving, managing and controlling the complete system, etc. In this paper, a Novel Rough Range of Value Method (R-ROV) for evaluating and selecting AGVs in the warehouse has been developed, which is one of the main contributions. In addition, the Full Consistency Method (FUCOM) was used to determine the weight values of the criteria. The model was formed through nine AGVs and 7 criteria. In the framework of checking the stability of the obtained results and the developed model, the comparison was performed using: Rough WASPAS (Weighted Aggregated Sum Product ASsessment), Rough SAW (Simple Additive Weighting) and Rough MABAC (Multi-Attributive Border Approximation area Comparison). Sensitivity analysis showed high correlation of ranks with all the applied methods by employing the Spearman's Correlation Coefficient (SCC).
\end{abstract}

Keywords: Rough Range Of Value (R-ROV), Full Consistency Method (FUCOM), Multi-Criteria Decision-Making (MCDM), Automatically Guided Vehicles (AGVs), Logistics.

\section{Introduction}

Logistics is constantly facing new challenges and is changing faster than ever before. The most obvious change can be seen in the increasing use of new technologies, especially information and communication technologies. Its application and role are visible at every step: electronic identification of packages, satellite tracking of vehicles, automatically guided vehicles, etc. One of the areas affected by the new logistics trends is the warehouse subsystem. Throughout history, the warehouses have undergone many changes, and various technologies have been implemented in them. Today, warehouses can function fully automatically. Many processes that are carried out in the warehouse from receipt and dispatch, internal transport, packaging, picking today are automated (Borovinšek et al., 2017; Izdebski et al., 2018; Janilionis, Bazaras \& Janilionis, 2016; Škerlič, Muha \& Sokolovskij, 2017). The aim of using MHE is to facilitate the handling of materials and production in warehouses and industrial transport. AGVs as an important type of MHE, play one of the key roles in warehouse and production facilities automation. The most commonly listed are four basic categories of such equipment: storage and handling equipment, engineering systems, industrial trucks, equipment for handling bulk materials (Fanisam et al., 2018). The main goal of applying new technologies for the mentioned purpose is saving energy and people, which significantly affects the reduction in the price of the final product (Kay, 2012). The selection and configuration of equipment for carrying out material handling tasks is very complex work because there are numerous limitations, opposing criteria, uncertainty, a wide range of equipment, etc. (Park, 1996). A key task in the material handling system design process according to the research conducted by Chan, Ip \& Lau, (2001) is the selection and configuration of equipment for material transport and storage in a facility.

The main aim of the paper is to develop a Novel R-ROV (Rough Range Of Value) method for solving multi-criteria decision-making problems. The development of this method enables an adequate treatment of the uncertainties and subjectivity that are inevitable in such models. Besides, the integration of R-ROV with FUCOM 
method is also a contribution in the literature that treats the Multi-Criteria Decision-Making (MCDM) problems.

In addition to the introductory considerations, there are 5 more sections. In the 2 nd section, a short literature review related to the application of different MCDM methods and of a hybrid approach for the evaluation and selection of the MHE is given. The 3rd section includes the methods used and consists of 3 parts. The 1st part presents the basic information and operations of the rough set theory. After that, a brief presentation and an explanation of the steps of FUCOM method are shown. In the 3rd subsection the steps of the novel R-ROV method are presented. The 4th section is a case study, which deals with evaluation and selection of AGVs in the warehouse. In this section, all calculations with the proposed methodology are given in detail. In the 5 th section a sensitivity analysis is presented in comparison with other Rough methods. In addition, the Spearman's Correlation Coefficient (SCC) has shown the stability of the obtained results in the proposed model. The last section presents the conclusion and the guidelines for future research.

\section{Literature review}

A number of approaches and techniques have been developed for the selection of adequate MHE, and most of them are based on the application of multi-criteria decision-making methods in various forms. That confirms Karande \& Chakraborty, (2013) in their research. According to them a wide variety of MHE is available today, and selection of the proper equipment is a complicated task. This is a multi-criteria decision-making problem and they used Weighted UTility Additive (WUTA) method to solve an MHE selection problem. Maniya \& Bhatt, (2011) are developed the new methodology for selection AGVs. They have proposed the Modified Grey Relational Analysis (M-GRA) method and Analytical Hierarchy Process (AHP). In (Azimi, Haleh \& Alidoost, 2010) a combination of Fuzzy AHP and TOPSIS (Technique for Order of Preference by Similarity to Ideal Solution) for selecting the best control strategy for AGVs is proposed. In addition, a two-phase methodology is applied in Aktan \& Tosun's research (2013) where authors used Fuzzy AHP and Fuzzy TOPSIS for selecting the suitable automated storage and retrieval system (AS/RS). They made a decision in an electronic company based on eleven criteria. The same methodology applied in Onut, Kara \& Mert' s research (2009) where authors made the decision about selecting the MHE types for a company in the steel construction industry in Istanbul. Fuzzy AHP is also applied in (Kumar $\&$ Raj, 2016) for ranking 3 alternatives according to 3 criteria, while the TOPSIS method is used in different forms (Sawant \& Mohite, 2013) for selecting one of the $16 \mathrm{AGVs}$ based on ten criteria.

The research conducted by Jiamruangjarus \& Naenna (2016) presents an integration of the Analytic Network Process (ANP) with the Benefits, Opportunities, Costs and Risk (BOCR) model in order to select the best conveyor system. Kulak, (2005) developed a decision support system for proper selection of MHE. The integration of the AHP method and experts systems is proposed in the paper of Chan, Ip \& Lau, (2001), in the frame of the system MHESA (Material Handling Equipment Selection Advisor). Tuzkaya et al. (2010) performed a combination of fuzzy sets, ANP and PROMETHEE method for MHE selection problem. The AHP method is adequately treating a large set of data, owing to forming a hierarchical structure. Taking this into account, the problem of equipment selection is divided into sub-criteria and therefore it is applied in (Chakraborty \& Banik, 2006). Hybrid model that implies the application of expert systems, fuzzy logic and genetic algorithm is developed in (Mirhosseyni \& Webb, 2009) for the selection and assignment of the most suitable MHE for all the MH operations in a production system. Saputro, Masudin \& Daneshvar Rouyendegh (2015) have presented the review paper of MHE based on 42 studies. They concluded that most of the researchers define MHE or equipment selection based on multi-criteria problem. In addition, they showed the advantages of applying a hybrid model (MCDM in integration with other approaches) for solving such problems.

\section{Methods}

\subsection{Rough set theory}

In rough set theory (Vasiljević et al., 2018; Roy et al., 2018; Radović et al., 2018), any vague idea can be represented as a couple of exact concepts based on the lower and upper approximations. That is shown in Figure 1. 


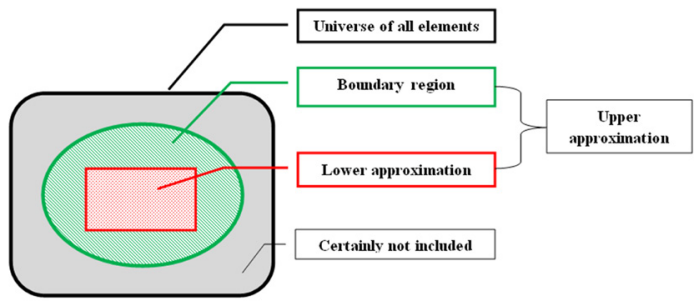

Figure 1. Elementary concept of rough set theory (Zavadskas et al., 2018)

Suppose $U$ is the universe which contains all the objects, $Y$ is an arbitrary object of $U, R$ is a set of $t$ classes $\left\{G_{1}, G_{2}, \ldots, G_{t}\right\}$ that cover all the objects in $U, R=\left\{G_{1}, G_{2}, \ldots, G_{t}\right\}$. If these classes are ordered as $\left.G_{1}<G_{2}<\ldots<G_{t}\right\}$, then $\forall Y \in U, G_{q} \in R, 1 \leq q \leq t$, by $R(Y)$ it is meant that the class to which the object belongs, the lower approximation $\left(\operatorname{Apr}\left(G_{q}\right)\right)$, upper approximation $\left(\overline{\operatorname{Apr}}\left(G_{q}\right)\right)$ and boundary region $\left(\overline{B n d}\left(G_{q}\right)\right)$ of class $G_{q}$ are defined as:

$$
\begin{aligned}
& \underline{\operatorname{Apr}}\left(G_{q}\right)=\left\{Y \in U / R(Y) \leq G_{q}\right\}, \\
& \overline{\operatorname{Apr}}\left(G_{q}\right)=\left\{Y \in U / R(Y) \geq G_{q}\right\} \text {, } \\
& \operatorname{Bnd}\left(G_{q}\right)=\left\{Y \in U / R(Y) \neq G_{q}\right\}= \\
& \left\{Y \in U / R(Y)>G_{q}\right\} \cup\left\{Y \in U / R(Y)<G_{q}\right\} \text {, }
\end{aligned}
$$

Then $G_{q}$ can be shown as a rough number $\left(R N\left(G_{q}\right)\right)$ which is determined by its corresponding lower limit $\left(\underline{\operatorname{Lim}}\left(G_{q}\right)\right)$ and upper limit $\left(\overline{\operatorname{Lim}}\left(G_{q}\right)\right)$ where

$$
\begin{aligned}
& \underline{\operatorname{Lim}}\left(G_{q}\right)=\frac{1}{M_{L}} \sum\left\{Y \in \underline{\operatorname{Apr}}\left(G_{q}\right)\right\} R(Y), \\
& \overline{\operatorname{Lim}}\left(G_{q}\right)=\frac{1}{M_{U}} \sum\left\{Y \in \overline{\operatorname{Apr}}\left(G_{q}\right)\right\} R(Y), \\
& R N\left(G_{q}\right)=\left[\underline{\operatorname{Lim}}\left(G_{q}\right), \overline{\operatorname{Lim}}\left(G_{q}\right)\right],
\end{aligned}
$$

where $M_{L}, M_{U}$ are the numbers of objects contained in $\underline{\operatorname{Apr}}\left(G_{q}\right)$ and $\overline{\operatorname{Apr}}\left(G_{q}\right)$, respectively.

The difference between them is expressed as a rough boundary interval $\left(\operatorname{IRBnd}\left(G_{q}\right)\right)$ :

$$
\operatorname{IRBnd}\left(G_{q}\right)=\overline{\operatorname{Lim}}\left(G_{q}\right)-\underline{\operatorname{Lim}}\left(G_{q}\right),
$$

The operations for two rough numbers $\quad R N(\alpha)=[\underline{\operatorname{Lim}}(\alpha), \overline{\operatorname{Lim}}(\alpha)] \quad$ and $R N(\beta)=[\underline{\operatorname{Lim}}(\beta), \overline{\operatorname{Lim}}(\beta)]$ are:
Addition $(+)$ of two rough numbers $R N(\alpha)$ and $R N(\beta)$ :

$$
R N(\alpha)+R N(\beta)=\left[\frac{\underline{\operatorname{Lim}}(\alpha)+\underline{\operatorname{Lim}}(\beta),}{\overline{\operatorname{Lim}}(\alpha)+\overline{\operatorname{Lim}}(\beta)}\right],
$$

Subtraction (-) of two rough numbers $R N(\alpha)$ and $R N(\beta)$ :

$$
R N(\alpha)-R N(\beta)=\left[\begin{array}{l}
\underline{\operatorname{Lim}}(\alpha)-\overline{\operatorname{Lim}}(\beta), \\
\overline{\operatorname{Lim}}(\alpha)-\underline{\operatorname{Lim}}(\beta)
\end{array}\right],
$$

Multiplication $(\times)$ of two rough numbers $R N(\alpha)$ and $R N(\beta)$ :

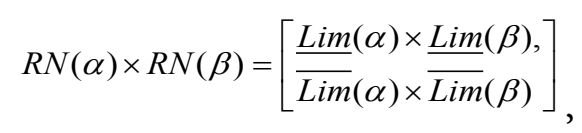

Division (/) of two rough numbers $R N(\alpha)$ and $R N(\beta)$ :

$$
R N(\alpha) / R N(\beta)=\left[\begin{array}{l}
\underline{\operatorname{Lim}}(\alpha) / \overline{\operatorname{Lim}}(\beta), \\
\overline{\operatorname{Lim}}(\alpha) / \underline{\operatorname{Lim}}(\beta)
\end{array}\right],
$$

Scalar multiplication of rough number $R N(\alpha)$, where $\mu$ is a nonzero constant:

$$
\mu \times R N(\alpha)=[\mu \times \underline{\operatorname{Lim}}(\alpha), \mu \times \overline{\operatorname{Lim}}(\alpha)],
$$

\subsection{FUCOM method}

The FUCOM method is developed by Pamučar, Stević \& Sremac, (2018) for determining the weights of criteria. According to the authors this new method is better than AHP (Analytical Hierarchy Process) and BWM (Best Worst Method). Until now is has been applied in Nunić's research (2018) and consists of the following 3 steps:

Step 1. In this step, the criteria from the predefined set of the evaluation criteria $C=\left\{C_{1}, C_{2}, \ldots, C_{n}\right\}$ are ranked. The ranking is performed according to the significance of the criteria, i.e. starting from the criterion, which is expected to have the highest weight coefficient to the criterion of the least significance.

$C_{j(1)}>C_{j(2)}>\ldots>C_{j(k)}$,

Step 2. In this step, a comparison between the ranked criteria is carried out and the comparative priority $\left(\varphi_{k /(k+1)}, k=1,2, \ldots, n\right.$, where $k$ represents the rank of the criteria) of the evaluation criteria is determined.

$\Phi=\left(\varphi_{1 / 2}, \varphi_{2 / 3}, \ldots, \varphi_{k /(k+1)}\right)$, 
Step 3. In this step, the final values of the weight coefficients of the evaluation criteria $\left(w_{1}, w_{2}, \ldots, w_{n}\right)^{T}$ are calculated. The final values of the weight coefficients should satisfy the following 2 conditions:

(a) the ratio of the weight coefficients is equal to the comparative priority among the observed criteria $\left(\varphi_{k^{\prime}(k+1)}\right)$ defined in Step 2, i.e. the following condition is met:

$$
\frac{w_{k}}{w_{k+1}}=\varphi_{k /(k+1)},
$$

(b) In addition to the Condition (2), the final values of the weight coefficients should satisfy the condition of mathematical transitivity, i.e. $\varphi_{k /(k+1)} \otimes \varphi_{(k+1) /(k+2)}=\varphi_{k /(k+2)}$.

Since $\quad \varphi_{k /(k+1)}=\frac{w_{k}}{w_{k+1}} \quad$ and $\quad \varphi_{(k+1) /(k+2)}=\frac{w_{k+1}}{w_{k+2}}$ $\frac{w_{k}}{w_{k+1}} \otimes \frac{w_{k+1}}{w_{k+2}}=\frac{w_{k}}{w_{k+2}}$ is obtained.

Thus, another condition that the final values of the weight coefficients of the evaluation criteria need to meet is obtained, namely:

$$
\frac{w_{k}}{w_{k+2}}=\varphi_{k /(k+1)} \otimes \varphi_{(k+1) /(k+2)} \text {, }
$$

Based on the defined settings, the final model for determining the final values of the weight coefficients of the evaluation criteria can be defined. $\min \chi$

s.t.

$\left|\frac{w_{j(k)}}{w_{j(k+1)}}-\varphi_{k /(k+1)}\right| \leq \chi, \forall j$

$\left|\frac{w_{j(k)}}{w_{j(k+2)}}-\varphi_{k /(k+1)} \otimes \varphi_{(k+1) /(k+2)}\right| \leq \chi, \forall j$

$\sum_{j=1}^{n} w_{j}=1, \forall j$

$w_{j} \geq 0, \forall j$

\subsection{A novel Rough ROV (R-ROV) method}

The ROV method was proposed by Yakowitz, Lane \& Szidarovszky (1993). It requires only ordinal specification of criteria importance from a decision maker. Thus, in situations where decision makers are facing problems in supplying quantitative weights, the application of the ROV method can be particularly useful. The ROV method calculates the best and worst utility for each alternative. This is achieved by maximizing and minimizing a utility function (Hajkowicz \& Higgin, 2008). This method computes all the possible combinations of cardinal values for indicator weights which are consistent with the decision maker's ordinal weighting and computes the range of possible values for the final score. In the literature ROV method has very limited applications. Few studies that have used this method can be found in Iş1k \& Adalı’s paper (2017).

In this paper, a novel R-ROV method has been developed, which is based precisely on the integration of the crisp ROV and rough numbers. The aim of this paper is to take advantages of rough numbers - reduction of subjectivity, uncertainty, and the advantages of the ROV method.

The R-ROV method consists of the following steps:

Step 1. Forming of the multi-criteria model. Define a set of criteria and alternatives for solving the multi-criteria problem.

Step 2. Forming a team of $e$ experts who will perform assessment of alternatives.

Step 3. Make conversion of individual responses of the experts into a group rough matrix $x_{j}$. Each response of the experts $e_{1}, e_{2}, \ldots, e_{n}$ should be converted into a rough group matrix using the Equations (1)-(6):

$R N(X)=\left[\begin{array}{cccc}{\left[x_{11}{ }^{L}, x_{11}\right]} & {\left[x_{12}{ }^{L}, x_{12}{ }^{U}\right]} & \cdots & {\left[x_{1 n}{ }^{L}, x_{1 n}{ }^{U}\right]} \\ {\left[x_{21}{ }^{L}, x_{21}\right]} & {\left[x_{22}{ }^{L}, x_{22}{ }^{U}\right]} & \cdots & {\left[x_{2 n}{ }^{L}, x_{2 n} U\right.} \\ \vdots & \vdots & \ddots & \vdots \\ {\left[x_{m 1}{ }^{L}, x_{m 1}\right]} & {\left[x_{m 2}{ }^{L}, x_{m 2}{ }^{U}\right]} & \cdots & {\left[x_{m n}{ }^{L}, x_{m n}\right]}\end{array}\right]$

Step 4. Normalization of the initial rough matrix $R N(X)$ in order to obtain the normalized matrix $R N(N)(19)$ :

$R N(N)=\left[\begin{array}{cccc}{\left[n_{11}{ }^{L}, n_{11}{ }^{U}\right]} & {\left[n_{12}{ }^{L}, n_{12}{ }^{U}\right]} & \cdots & {\left[n_{1 n}{ }^{L}, n_{1 n}{ }^{U}\right]} \\ {\left[n_{21}{ }^{L}, n_{21}{ }^{U}\right]} & {\left[n_{22}{ }^{L}, n_{22}{ }^{U}\right]} & \cdots & {\left[n_{2 n}{ }^{L}, n_{2 n}{ }^{U}\right]} \\ \vdots & \vdots & \ddots & \vdots \\ {\left[n_{m 1}{ }^{L}, n_{m 1}{ }^{U}\right]} & {\left[n_{m 2}{ }^{L}, n_{m 2}{ }^{U}\right]} & \cdots & {\left[n_{m n}{ }^{L}, n_{m n}{ }^{U}\right]}\end{array}\right]$ 
Normalization of an initial rough matrix includes 2 phases depending on the type of criteria. The 1 st phase relates to the normalization of benefit criteria by using Equation (20).

$n_{i j}{ }^{L}=\frac{x_{i j}^{L}-x_{j}^{-}}{x_{j}{ }^{+}-x_{j}^{-}}$and $n_{i j}{ }^{U}=\frac{x_{i j}^{U}-x_{j}^{-}}{x_{j}^{+}-x_{j}^{-}}$

The 2 nd phase relates to the normalization of cost criteria by using Equation (21).

$$
n_{i j}^{L}=\frac{x_{i j}^{U}-x_{j}^{+}}{x_{j}^{-}-x_{j}^{+}} \text {and } n_{i j}^{U}=\frac{x_{i j}^{L}-x_{j}^{+}}{x_{j}^{-}-x_{j}^{+}}
$$

where

$$
\begin{aligned}
& x_{j}^{+}=\left\{\begin{array}{llll}
\max _{j=1}^{m} x_{j}^{U} & \text { for } & \text { benefit criteria } \\
\min _{j=1} x_{j}^{L} & \text { for } & \cos t \quad \text { criteria }
\end{array}\right. \\
& x_{j}^{-}=\left\{\begin{array}{llll}
\min _{j=1}^{m} x_{j}^{L} & \text { for } & \text { benefit criteria } \\
\max _{j=1} x_{j}^{U} & \text { for } & \cos t & \text { criteria }
\end{array}\right.
\end{aligned}
$$

where $m$ represents the number of criteria.

Step 5. Weighting the normalized rough matrix using Equation (22)

$$
\begin{aligned}
& W_{n}=\left[w_{i j}{ }^{L} ; w_{i j}^{U}\right]_{m \times n} \\
& w_{i j}=w_{j}^{L} \times n_{i j}^{L}, \quad i=1,2, \ldots, n ; \quad j=1,2, \ldots, m \\
& w_{i j}=w_{j}^{U} \times n_{i j}^{U}, \quad i=1,2, \ldots, n ; \quad j=1,2, \ldots, m
\end{aligned}
$$

Step 6. In this step the sums of weighted normalized values are calculated for both the benefit criteria using the following Equation (23):

$U_{i}^{+}=\sum_{j=1}^{m}\left[w_{i j}^{L+} ; w_{i j}^{U+}\right]_{1 x n}$

and the cost criteria by using the following Equation (24):

$$
U_{i}^{-}=\sum_{j=1}^{m}\left[w_{i j}^{L-} ; w_{i j}^{U-}\right]_{1 x n}
$$

Step 7. Calculation of final values for all alternatives using Equation (25):

$$
A_{i}=\frac{U_{i}^{+}+U_{i}^{-}}{2}
$$

Step 8. Ranking the alternatives in decreasing order. The alternative with highest value is the best, while the alternative with the smallest value is the worst.

\section{Selection of AGVs using FUCOM and R-ROV method}

\subsection{Forming of Multi-criteria model}

The verification of the proposed novel R-ROV method was carried out by the selection of MHE in a warehouse. A FUCOM method is applied for determining the weights of the criteria for the selection of AGVs. This multi-criteria model includes 7 criteria and nine AGVs solutions. A total of 3 experts performed the assessment of criteria and alternatives.

Nine alternatives shown in Figure 2 are evaluated according to 7 criteria: $\mathrm{C} 1$ - dimensions ( $\mathrm{min}$ ), $\mathrm{C} 2$ - minimum lift height (min), C3 - price (min), C4 - capacity of AGVs (max), C5 - battery capacity of AGVs (max), C6 - maximum lift height (max) and $\mathrm{C} 7$ - speed of AGVs (max). The 1st 3 criteria belong to cost criteria, while the other four belong to benefit criteria.

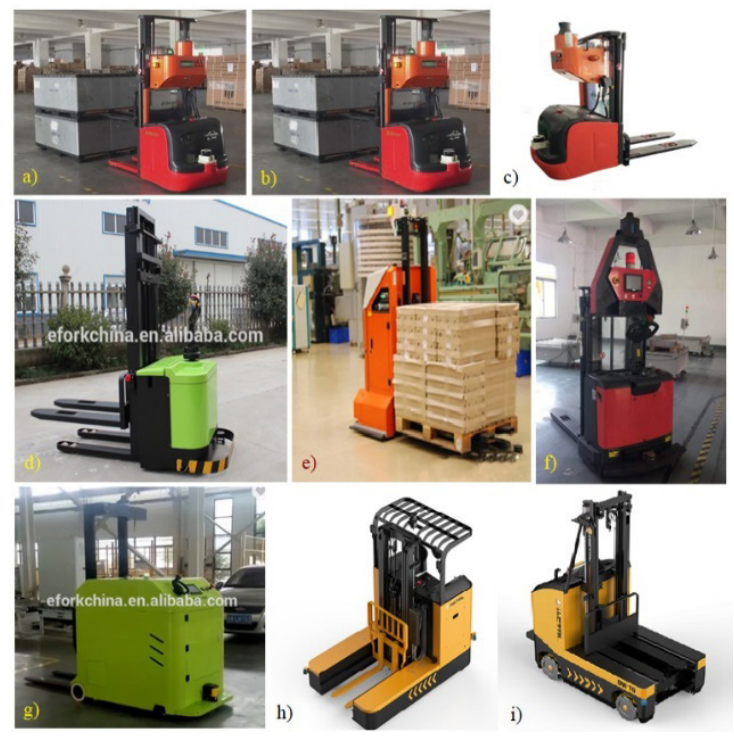

Figure 2. Alternatives - AGVs solutions

\subsection{Determining criteria weight using the FUCOM method}

Step 1. In this step, the decision-makers performed the ranking of the criteria based on the consensus: $\mathrm{C} 4=\mathrm{C} 7>\mathrm{C} 1>\mathrm{C} 3>\mathrm{C} 6>\mathrm{C} 5>\mathrm{C} 2$.

Step 2. In this step the decision-maker performs a pairwise comparison between the ranked criteria from Step 1. The comparison is made with respect to the 1st-ranked $\mathrm{C} 4$ criterion. The comparison is based on the scale $[1,9]$. Thus, the priorities of criteria $\left(\varpi_{C_{i(k)}}\right)$ for all of the criteria ranked in Step 1 are obtained (Table 1$)$. 
Table 1. Priorities of criteria

\begin{tabular}{|l|l|l|l|l|l|l|l|}
\hline Crit. & C4 & C7 & C1 & C3 & C6 & C5 & C2 \\
\hline$\varpi_{C_{j(k)}}$ & 1 & 1 & 1.5 & 1,5 & 2,6 & 2,9 & 3,1 \\
\hline
\end{tabular}

Based on the obtained priorities of the criteria, the comparative priorities of the criteria are calculated

$\varphi_{C 4 / C 7}=1 / 1=1$,

$\varphi_{C 7 / C 1}=1.5 / 1=1.5, \varphi_{C 1 / C 3}=1.9 / 1.5=1.27$,

$\varphi_{C 3 / C 6}=2.6 / 1.9=1.37, \varphi_{C 6 / C 5}=2.9 / 2.6=1.11$,

$\varphi_{C 5 / C 2}=3.1 / 2.9=1.07$

Step 3. The final values of the weight coefficients should meet the following 2 conditions:

(a) The final values of the weight coefficients should meet Condition (2), i.e. that $w_{4} / w_{7}=1$,

$w_{7} / w_{1}=1.5$

$w_{1} / w_{3}=1.27$,

$w_{3} / w_{6}=1.37$,

$w_{6} / w_{5}=1.11$,

$w_{5} / w_{2}=1.07$

(b) In addition to Condition (2), the final values of the weight coefficients should meet the condition of mathematical transitivity, i.e. that:

$w_{4} / w_{1}=1 \cdot 1.5=1.5$,

$w_{7} / w_{3}=1.5 \cdot 1.27=1.91$

$w_{1} / w_{6}=1.27 \cdot 1.37=1.74$

$w_{3} / w_{5}=1.37 \cdot 1.11=1.52$

$w_{6} / w_{2}=1.11 \cdot 1.07=1.19$

By applying Expression (17), the final model for determining the weight coefficients can be defined as:

$\min \chi$

$$
\text { s.t. }\left\{\begin{array}{l}
\left|\frac{w_{4}}{w_{7}}-1\right|=\chi,\left|\frac{w_{7}}{w_{1}}-1.5\right|=\chi,\left|\frac{w_{1}}{w_{3}}-1.27\right|=\chi, \\
\left|\frac{w_{3}}{w_{6}}-1.37\right|=\chi,\left|\frac{w_{6}}{w_{5}}-1.11\right|=\chi,\left|\frac{w_{5}}{w_{1}}-1.07\right|=\chi,\left|\frac{w_{7}}{w_{3}}-1.91\right|=\chi,\left|\frac{w_{1}}{w_{6}}-1.74\right|=\chi, \\
\left|\frac{w_{3}}{w_{5}}-1.52\right|=\chi\left|\frac{w_{6}}{w_{2}}-1.19\right|=\chi \\
\sum_{j=1}^{7} w_{j}=1, w_{j} \geq 0, \forall j
\end{array}\right.
$$

By solving this model, the final values of the weight coefficients are $0.157,0.076,0.124,0.236$, $0.081,0.09,0.236$ and the DFC of the results are $\chi=0.0013$ or $0.13 \%$. The obtained DFC show the total objectivity obtained results, that allows the application of the FUCOM method.

By applying the FUCOM method, the criteria weights are obtained. The results show that the most important criteria for solving this problem are the 4th and 7th criterion with value of 0.236 . After that is the 1st criteria with value of 0.157 . These are followed by the 3rd criterion with a value of 0.124 , the 6th criterion with a value of 0.09 , the 5 th criterion with a value of 0.081 and by the 2 nd criterion with a value of 0.076 .

\subsection{Selection of AGVs using Rough ROV

\begin{tabular}{|c|c|c|c|c|c|c|c|c|}
\hline & & $\mathrm{A} 1$ & A2 & A3 & $\ldots$ & A7 & A8 & A9 \\
\hline \multirow{3}{*}{$\mathrm{C} 1$} & E1 & 1 & 1 & 1 & & 5 & 7 & 5 \\
\hline & E2 & 1 & 1 & 1 & & 7 & 7 & 3 \\
\hline & E3 & 3 & 3 & 3 & & 7 & 7 & 5 \\
\hline \multirow{3}{*}{$\mathrm{C} 2$} & E1 & 3 & 3 & 3 & & 1 & 1 & 1 \\
\hline & E2 & 5 & 5 & 5 & & 3 & 3 & 3 \\
\hline & E3 & 3 & 3 & 3 & & 1 & 1 & 1 \\
\hline \multirow{3}{*}{ C3 } & E1 & 7 & 7 & 7 & & 9 & 5 & 5 \\
\hline & E2 & 5 & 5 & 5 & & 7 & 3 & 3 \\
\hline & E3 & 5 & 5 & 5 & & 9 & 3 & 3 \\
\hline \multirow{3}{*}{$\mathrm{C} 4$} & E1 & 5 & 5 & 7 & & 7 & 5 & 7 \\
\hline & E2 & 5 & 5 & 7 & & 7 & 5 & 5 \\
\hline & E3 & 5 & 5 & 9 & . & 9 & 7 & 7 \\
\hline \multirow{3}{*}{ C5 } & E1 & 5 & 5 & 5 & & 3 & 5 & 9 \\
\hline & E2 & 5 & 5 & 7 & & 3 & 5 & 9 \\
\hline & E3 & 3 & 3 & 5 & & 1 & 3 & 9 \\
\hline \multirow{3}{*}{ C6 } & E1 & 7 & 9 & 5 & & 7 & 7 & 7 \\
\hline & E2 & 5 & 9 & 5 & & 5 & 5 & 5 \\
\hline & $\overline{\mathrm{E} 3}$ & 5 & 9 & 3 & & 5 & 5 & 5 \\
\hline \multirow{3}{*}{ C7 } & E1 & 5 & 5 & 5 & & 9 & 1 & 1 \\
\hline & E2 & 7 & 7 & 7 & & 9 & 3 & 3 \\
\hline & E3 & 7 & 7 & 7 & & 9 & 3 & 3 \\
\hline
\end{tabular} method}

Table 2. Linguistic scale for evaluating the alternatives

\begin{tabular}{|l|c|c|}
\hline \multicolumn{1}{|c|}{ Linguistic scale } & $\begin{array}{c}\text { For benefit } \\
\text { criteria }\end{array}$ & $\begin{array}{c}\text { For cost } \\
\text { criteria }\end{array}$ \\
\hline Very Poor - VP & 1 & 9 \\
\hline Poor - P & 3 & 7 \\
\hline Medium - M & 5 & 5 \\
\hline Good - G & 7 & 3 \\
\hline Very Good - VG & 9 & 1 \\
\hline
\end{tabular}

Table 3. Assessment of alternatives by $3 \mathrm{DMs}$ 
The 1st step of the R-ROV method is was explained in a previous subsection. The model includes an expert team of 3 members. They have performed assessment of alternatives which is shown in Table 3 based on the linguistic scale defined in Stević et al.'s research (2017) and presented in Table 2.

Forming a team of $e$ experts who have performed assessment of alternatives represents the 2 nd step of this method.

In Step 3 each response of the experts $e_{1}, e_{2}, \ldots, e_{n}$ is converted into a rough group matrix using Equations (1)-(6). An example of the transformation of the crisp elements into the rough matrix is:

For the 1st alternative according to 1 st criterion $\tilde{x}_{11}=\{1,1,3$,$\} will be:$

$$
\begin{aligned}
& \underline{\operatorname{Lim}}(1)=1, \overline{\operatorname{Lim}}(1)=\frac{1}{3}(1+1+3)=1.67 \\
& \underline{\operatorname{Lim}}(3)=\frac{1}{3}(1+1+3)=1.67, \overline{\operatorname{Lim} 3}=3 \\
& R N\left(c_{1}^{1}\right)=R N\left(c_{1}^{2}\right)=[1.00,1.67] ; \\
& R N\left(c_{1}^{3}\right)=[1.67,3.00] \\
& c_{1}^{L}=\frac{c_{1}^{1}+c_{1}^{2}+c_{1}^{3}}{n}=\frac{1.00+1.00+1.67}{3}=1.22 \\
& c_{1}^{U}=\frac{c_{1}^{1}+c_{1}^{2}+c_{1}^{3}}{n}=\frac{1.67+1.67+3.00}{3}=2.11
\end{aligned}
$$

\begin{tabular}{|c|c|c|c|c|c|c|}
\hline & \multicolumn{2}{|c|}{$\mathrm{C}_{1}$} & \multicolumn{2}{|c|}{$\mathrm{C}_{2}$} & \multicolumn{2}{|c|}{$\mathrm{C}_{7}$} \\
\hline$A_{1}$ & 1.22 & 2.11 & 3.22 & 4.11 & 5.89 & 6.78 \\
\hline $\mathrm{A}_{2}$ & 1.22 & 2.11 & 3.22 & 4.11 & 5.89 & 6.78 \\
\hline $\mathrm{A}_{3}$ & 1.22 & 2.11 & 3.22 & 4.11 & 5.89 & 6.78 \\
\hline $\mathrm{A}_{4}$ & 3.89 & 4.78 & 1.22 & 2.11 & 9.00 & 9.00 \\
\hline $\mathrm{A}_{5}$ & 1.22 & 2.11 & 3.22 & 4.11 & 5.89 & 6.78 \\
\hline $\mathrm{A}_{6}$ & 5.22 & 6.11 & 6.00 & 8.00 & 9.00 & 9.00 \\
\hline $\mathrm{A}_{7}$ & 5.89 & 6.78 & 1.22 & 2.11 & 9.00 & 9.00 \\
\hline $\mathrm{A}_{8}$ & 7.00 & 7.00 & 1.22 & 2.11 & 1.89 & 2.78 \\
\hline $\mathrm{A}_{9}$ & 3.89 & 4.78 & 1.22 & 2.11 & 1.89 & 2.78 \\
\hline
\end{tabular}

On the same way is obtained all the initial rough group matrix shown in Table 4.

Table 4. Initial rough matrix

An example of normalization of the initial matrix in Step 4 for benefit criteria is the following:

$n_{44}{ }^{L}=\frac{1.22-1.22}{9.00-1.22}=0.00 ; n_{44}{ }^{U}=\frac{2.11-1.22}{9.00-1.22}=0.11$
And for cost criteria:

$n_{11}{ }^{L}=\frac{2.11-7.00}{1.22-7.00}=0.85 ; n_{11}{ }^{U}=\frac{1.22-7.00}{1.22-7.00}=1.00$

The normalized rough matrix is shown in Table 5. The biggest value of the cost criteria must be zero, while for the benefit criteria it must be one. The smallest value of the cost criteria has to be one, while for the benefit criteria it has to be zero in the normalized matrix.

In Step 5 the normalized matrix is weighted with the values obtained using the FUCOM method. After that in the 6th step the sums of the weighted normalized values are calculated for both the type of the criteria using Equations (21) and (22). The

\begin{tabular}{|c|c|c|c|c|c|c|}
\hline & \multicolumn{2}{|c|}{$\mathrm{C}_{1}$} & \multicolumn{2}{|c|}{$\mathrm{C} 2$} & \multicolumn{2}{|c|}{$\mathrm{C} 7$} \\
\hline $\mathrm{A}_{1}$ & 0.85 & 1.00 & 0.57 & 0.71 & 0.56 & 0.69 \\
\hline $\mathrm{A}_{2}$ & 0.85 & 1.00 & 0.57 & 0.71 & 0.56 & 0.69 \\
\hline $\mathrm{A}_{3}$ & 0.85 & 1.00 & 0.57 & 0.71 & 0.56 & 0.69 \\
\hline $\mathrm{A}_{4}$ & 0.38 & 0.54 & 0.87 & 1.00 & 1.00 & 1.00 \\
\hline $\mathrm{A}_{5}$ & 0.85 & 1.00 & 0.57 & 0.71 & 0.56 & 0.69 \\
\hline $\mathrm{A}_{6}$ & 0.15 & 0.31 & 0.00 & 0.29 & 1.00 & 1.00 \\
\hline $\mathrm{A}_{7}$ & 0.04 & 0.19 & 0.87 & 1.00 & 1.00 & 1.00 \\
\hline $\mathrm{A}_{8}$ & 0.00 & 0.00 & 0.87 & 1.00 & 0.00 & 0.13 \\
\hline $\mathrm{A}_{9}$ & 0.38 & 0.54 & 0.87 & 1.00 & 0.00 & 0.13 \\
\hline
\end{tabular}
7 th step presents the calculation of the final values for all alternatives using Equation (23). The final results of the applied FUCOM - Rough ROV method are presented in Table 6 .

Table 5. Normalized rough matrix

Table 6. Final results of FUCOM - Rough ROV method

\begin{tabular}{|c|c|c|c|c|c|c|c|}
\hline & \multicolumn{2}{|c|}{$\mathrm{U}-$} & \multicolumn{2}{c|}{$\mathrm{U}+$} & \multicolumn{2}{|c|}{ Ui } & Rank \\
\hline $\mathrm{A}_{1}$ & 0.219 & 0.267 & 0.312 & 0.363 & 0.266 & 0.315 & $\mathbf{5}$ \\
\hline $\mathrm{A}_{2}$ & 0.219 & 0.267 & 0.360 & 0.400 & 0.290 & 0.334 & $\mathbf{3}$ \\
\hline $\mathrm{A}_{3}$ & 0.219 & 0.267 & 0.378 & 0.456 & 0.299 & 0.362 & $\mathbf{1}$ \\
\hline $\mathrm{A}_{4}$ & 0.222 & 0.270 & 0.236 & 0.284 & 0.229 & 0.277 & $\mathbf{8}$ \\
\hline $\mathrm{A}_{5}$ & 0.219 & 0.267 & 0.392 & 0.443 & 0.305 & 0.355 & $\mathbf{2}$ \\
\hline $\mathrm{A}_{6}$ & 0.148 & 0.195 & 0.407 & 0.456 & 0.278 & 0.325 & $\mathbf{4}$ \\
\hline $\mathrm{A}_{7}$ & 0.072 & 0.120 & 0.460 & 0.509 & 0.266 & 0.314 & $\mathbf{6}$ \\
\hline $\mathrm{A}_{8}$ & 0.140 & 0.165 & 0.186 & 0.264 & 0.163 & 0.214 & $\mathbf{9}$ \\
\hline $\mathrm{A}_{9}$ & 0.201 & 0.249 & 0.265 & 0.333 & 0.233 & 0.291 & $\mathbf{7}$ \\
\hline
\end{tabular}

The final results show that the 3rd AGVs represents the best alternative, while the 5th AGVs also represents a very good solution. 


\section{Sensitivity analysis in comparison with other methods}

In order to check the stability of the developed R-ROV approach a sensitivity analysis has been performed. Figure 3 shows the sensitivity analysis by applying different rough approaches: Rough WASPAS - Weighted Aggregated Sum Product ASsessment (Stojić et al., 2018), Rough SAW Simple Additive Weighting (Stević et al., 2017) and Rough MABAC - Multi-Attributive Border Approximation area Comparison (Roy et al., 2017).

In Figure 3, it can be seen that the 3rd alternative is on the 1st place using R-ROV and Rough WASPAS method, while using the rest 2 methods (Rough MABAC and Rough SAW) it is on the 2nd position. The same situation from the aspect of the applied methods is with the 5th alternative that is on the 1st and 2nd positions. Using R-ROV and Rough MABAC the 1st alternative has the same position (5th), while using other 2 methods it is on the 6th place. Alternative A2, A4, A8 and A9 have equal positions using all the methods. The biggest change has the 7th alternative that varies from 4th (Rough SAW and Rough WASPAS) to 6th position (Rough ROV and Rough MABAC).

Table 7 shows the checking of the correlation of ranks using different rough approaches.

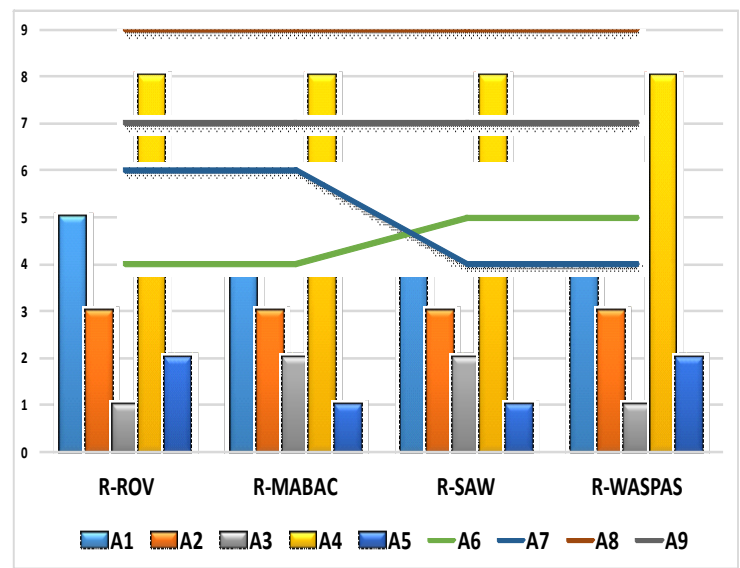

Figure 3. Ranking alternatives trough different Rough MCDM methods

Table 7 shows the Spearman's correlation coefficient for all the four used rough methods according to which it can be concluded that the ranks in all methods are in very high correlation. This is confirmed by the average value of SCC for all the methods which is 0.980 . The values of SCC vary from 0.933 to 1.00 . The developed novel R-ROV method has the highest correlation of ranks with rough MABAC (0.983), while with other methods it has a lower correlation (0.950 with Rough WASPAS) and 0.933 with Rough SAW. The interesting situation is that no method has a full correlation with another method.

Table 7. Statistical SCC of ranks for different rough methods

\begin{tabular}{|l|c|c|c|c|c|}
\hline Methods & RR & RM & RS & RW & AV \\
\hline RR & 1.000 & 0.983 & 0.933 & 0.950 & 0.967 \\
\hline RM & - & 1.000 & 0.950 & 0.933 & 0.961 \\
\hline RS & - & - & 1.000 & 0.983 & 0.992 \\
\hline RW & - & - & - & 1.000 & 1.000 \\
\hline \multicolumn{7}{|c|}{ Overall average } & 0.980 \\
\hline $\begin{array}{l}\text { RR - Rough ROV; RM - Rough MABAC; RS - Rough } \\
\text { SAW; RW - Rough WASPAS; AV - Average }\end{array}$
\end{tabular}

\section{Conclusion}

Warehousing as logistics subsystem represents an important link in logistics chain, which offers numerous opportunities for optimization. In this paper the problem of warehouse automation through the evaluation and selection of AGVs is considered. As a component of MHE, AGVs represent a solution that can greatly improve the operation process in the warehouse itself, and therefore in the entire supply chain. It is clear that their use can save energy, so that a lower price of the final product can also be expected if it comes to production plants.

The developed approach presented in this research refers to the integration of Rough numbers and Range Of Value (ROV) method. The model has been verified in the process of evaluating and selecting the automatically guided vehicles in warehouse. The main aim of this study is to take the advantages of rough numbers and the advantages of the ROV method. The algorithm of the R-ROV method consists of eight steps and in each step, the calculation has been explained in detail through a verification model.

In order to determine the stability of the results obtained, a sensitivity analysis has been performed in which 3 other Rough methods have been applied: Rough MABAC, Rough SAW and Rough WASPAS method. The performed sensitivity analysis shows that the developed R-ROV method provides stable and valid results. Analyzing the results obtained by calculating the Spearman's correlation coefficient, it has been found that the obtained alternative ranks of the $\mathrm{R}-\mathrm{ROV}$ approach are in high correlation with the 
ranks of other method. The main contribution of this paper is represented by the development of the novel R-ROV method and integration with FUCOM method that ensures an objective aggregation of the decisions with absolute respect for inaccuracies and subjectivity that prevails in group decision-making. The novel R-ROV method

\section{REFERENCES}

1. Aktan,H.E.\& Tosun, Ö.(2013). An integrated fuzzy AHP-fuzzy TOPSIS approach for AS/RS selection, International Journal of Productivity and Quality Management, 11(2), 228-245.

2. Azimi, P., Haleh, H. \& Alidoost, M. (2010). The selection of the best control rule for a multiple-load AGV system using simulation and fuzzy MADM in a flexible manufacturing system, Modelling and Simulation in Engineering, ID 821701, 1-11.

3. Borovinšek, M., Ekren, Y. B., Burinskienè, A., \& Lerher, T. (2017). Multi-objective optimisation model of shuttle-based storage and retrieval system, Transport, $32(2), 120-137$.

4. Chakraborty, S. \& Banik, D. (2006). Design of a material handling equipment selection model using analytic hierarchy process, The International Journal of Advanced Manufacturing Technology, 28(11-12), 1237-1245.

5. Chan, F. T. S., Ip, R. W. L. \& Lau, H. (2001). Integration of expert system with analytic hierarchy process for the design of material handling equipment selection system, Journal of Materials Processing Technology, 116(2-3), 137-145.

6. Fanisam, M. BN., Dewa, B., Ayush, M., Yogesh, M. \& Harshal, M. (2018). Material handling equipment, International Journal of Recent Scientific Research 9(2(E)), 24083-24085.

7. Hajkowicz, S. \& Higgins, A. (2008). A comparison of multiple criteria analysis techniques for water resource management, European journal of operational research, 184(1), 255-265.

8. Işık, A. T. \& Adal1, E. A. (2017). The decisionmaking approach based on the combination of entropy and ROV methods for the apple contributes to the improvement of literature in which the theoretical and practical application of multi-criteria methods is considered. The developed approach enables the solving of multicriteria decision-making problems regardless of the inaccuracies and the lack of quantitative information in decision-making.

selection problem, European Journal of Interdisciplinary Studies, 3(3), 80-86.

9. Izdebski, M., Jacyna-Gołda, I., Wasiak, M., Jachimowski, R., Kłodawski, M., Pyza, D. \& Żak, J. (2018). The application of the genetic algorithm to multi-criteria warehouses location problems on the logistics network, Transport, 33(3), 741-750.

10. Janilionis, V. V., Bazaras, Ž. \& Janilionis, V. (2016). Comparison of routing algorithms for storage and retrieval mechanism in cylindrical AS/RS, Transport, 31(1), 11-21.

11. Jiamruangjarus, P. \& Naenna, T. (2016). An integrated multi-criteria decision-making methodology for conveyor system selection, Cogent Engineering, 3(1), ID 1158515.

12. Karande, P. \& Chakraborty, S. (2013). Material handling equipment selection using weighted utility additive theory, Journal of Industrial Engineering, ID 268708, 1-9.

13. Kay, M. G. (2012). Material handling equipment. Fitts Department of Industrial and Systems Engineering, North Carolina State University, US. 67 p. Retrieved from: $<$ https://people.engr.ncsu.edu/kay/Material_ HaHandli_Equipment.pdf $>$.

14. Kulak, O. (2005). A decision support system for fuzzy multi-attribute selection of material handling equipments, Expert Systems with Applications, 29(2), 310-319.

15. Kumar, S. \& Raj, T. (2016). Selection of material handling equipment for flexible manufacturing system using FAHP, International Journal of Recent Advances in Mechanical Engineering, 5(1), 25-45.

16. Maniya, K. D. \& Bhatt, M. G. (2011). A multi-attribute selection of automated guided vehicle using the AHP/M-GRA technique, International Journal of Production Research, 49(20), 6107-6124. 
17. Mirhosseyni, S. H. L. \& Webb, P. (2009). A hybrid fuzzy knowledge-based expert system and genetic algorithm for efficient selection and assignment of material handling equipment, Expert Systems with Applications, 36(9), 11875-11887.

18. Nunić, Z. (2018). Evaluation and selection of the PVC carpentry Manufacturer using the FUCOM-MABAC model, Operational Research in Engineering Sciences: Theory and Applications, 1(1), 13-28.

19. Onut, S., Kara, S. S. \& Mert, S. (2009). Selecting the suitable material handling equipment in the presence of vagueness, The International Journal of Advanced Manufacturing Technology, 44(7-8), 818-828.

20. Pamučar, D., Stević, Ž. \& Sremac, S. (2018). A new model for determining weight coefficients of criteria in MCDM models: Full Consistency Method (FUCOM), Symmetry, 10(9), ID 393, 1-22.

21. Park, Y. B. (1996). ICMESE: intelligent consultant system for material handling equipment selection and evaluation, Journal of Manufacturing Systems, 15(5), 325-333.

22. Radović, D., Stević, Ž., Pamučar, D., Zavadskas, E. K., Badi, I., Antuchevičiene, J. \& Turskis, Z. (2018). Measuring performance in transportation companies in developing countries: A novel rough ARAS model, Symmetry, 10(10), ID 434.

23. Roy, J., Adhikary, K., Kar, S. \& Pamucar, D. (2018). A rough strength relational DEMATEL model for analysing the key success factors of hospital service quality, Decision Making: Applications in Management and Engineering, 1(1), 121-142.

24. Roy, J., Chatterjee, K., Bandhopadhyay, A. \& Kar, S. (2017). Evaluation and selection of medical tourism sites: A rough analytic hierarchy process based multi attributive border approximation area comparison approach, Expert Systems, 35(1), ID e12232, $1-19$.

25. Saputro, T. E., Masudin, I. \& Daneshvar Rouyendegh, B. (2015). A literature review on MHE selection problem: levels, contexts, and approaches, International Journal of Production Research, 53(17), 5139-5152.

26. Sawant, V. B. \& Mohite, S. S. (2013). A composite weight based multiple attribute decision support system for the selection of automated guided vehicles, International Journal of Computer Applications, 70(19), 8-16.

27. Škerlič, S., Muha, R. \& Sokolovskij, E. (2017). Application of modern warehouse technology in the Slovenian automotive industry, Transport, 32(4), 415-425.

28. Stanujkić, D. \& Karabašević, D. (2018). An extension of the WASPAS method for decision-making problems with intuitionistic fuzzy numbers: a case of website evaluation, Operational Research in Engineering Sciences: Theory and Applications, 1(1), 29-39.

29. Stević, Ž., Pamučar, D., Kazimieras Zavadskas, E., Ćirović, G. \& Prentkovskis, O. (2017). The selection of wagons for the internal transport of a logistics company: A novel approach based on rough BWM and rough SAW methods, Symmetry, 9(11), ID 264, 1-25.

30. Stojić, G., Stević, Ž., Antuchevičienė, J., Pamučar, D. \& Vasiljević, M. (2018). A novel rough WASPAS approach for supplier selection in a company manufacturing PVC carpentry products, Information, 9(5), ID 121.

31. Tuzkaya, G., Gülsün, B., Kahraman, C. \& Özgen, D. (2010). An integrated fuzzy multi-criteria decision making methodology for material handling equipment selection problem and an application, Expert systems with applications, 37(4), 2853-2863.

32. Vasiljević, M., Fazlollahtabar, H., Stević, Ž. \& Vesković, S. (2018). A rough multicriteria approach for evaluation of supplier criteria in automotive industry, Decision Making: Applications in Management and Engineering, 1(1), 82-96.

33. Yakowitz, D. S., Lane, L. J. \& Szidarovszky, F. (1993). Multi-attribute decision making: dominance with respect to an importance order of the attributes, Applied Mathematics and Computation, 54(2-3), 167-181.

34. Zavadskas, E. K., Stević, Ž., Tanackov, I. \& Prentkovskis, O. (2018). A novel multicriteria approach - Rough Step-Wise Weight Assessment Ratio Analysis method (R-SWARA) and its application in logistics, Studies in Informatics and Control, 27(1), 97-106. doi:10.24846/v27i1y201810 